\title{
FEASIBILITY OF USING HYPERSPECTRAL REMOTE SENSING FOR ENVIRONMENTAL HEAVY METAL MONITORING
}

\author{
Xin-Yu Chen, Hui-Chun Lee, Mengshan Lee* \\ Department of Safety, Health and Environmental Engineering, National Kaohsiung University of Science and Technology, \\ Kaohsiung, Taiwan
}

Commission III, WG III/10

KEY WORDS : Remote sensing; Hyperspectral data; Heavy metals; Non-destructive analysis; XRF; Pollution management strategy

\begin{abstract}
:
The use of optical properties as key parameters has been widely used in water quality monitoring, which accelerates the advances of remote sensing in the field of environmental monitoring. Current analytical methods for determining heavy metals in water include flame atomic absorption spectrometry (FAAS), atomic adsorption spectrophotometry (AAS) and inductively coupled plasma (ICP) spectroscopy, which typically require use of chemicals for sample processing and pretreatment as well as high capital input for analysis. Therefore, this study aims at investigating the potential of using non-destructive approaches for rapid water monitoring of heavy metal from green chemistry perspective. The proposed non-destructive sensing techniques include X-ray fluorescence spectrometer (XRF) and visible-near infrared spectroradiometer (VNIR). The former is an elemental analyser specifically for elements with relatively high atomic number, and the latter measures the reflectance or transmittance from samples. Heavy metals of lead $(\mathrm{Pb})$, zinc $(\mathrm{Zn})$ and copper $(\mathrm{Cu})$ were selected as the target water constitutes in the study. The results from the analysis were then be used for determining a correlation model through chemometric approaches. Our results demonstrated that both of the target metals could be analysed via the proposed analytical methods. Reasonable agreements between the measurements from XRF and ICP were observed, whereas moderate correlations were perceived for simple linear regression model using spectral information from VNIR. Results from this study are expected to provide useful information on rapid identification of metal-polluting sources.
\end{abstract}

\section{INTRODUCTION}

Current conventional analytical methods for determining heavy metals in water include atomic absorption/emission spectroscopy (AAS), inductively coupled plasma mass spectrometry (ICP-MS) and cold vapour atomic fluorescence spectrometry (CV-AFS), which all require use of chemicals for sample processing and pre-treatment as well as high capital input for sampling and analysis. The demand for good quality, real-time, non-destructive and high resolution water quality information therefore has been growing in research areas of environmental monitoring, in order to comply with the concept of green chemistry.

The use of optical properties as key parameters has been widely used in environmental monitoring. Recent efforts were therefore made in the development of emerging analytical approach using non-destructive spectroscopic techniques, including laser induced breakdown spectrometry (LIBS), X-ray fluorescence (XRF) and visible-near infrared spectroradiometer (VNIR). Use of hyperspectral technique for determination of heavy metal in environmental samples were seldom reported, especially for water bodies. Rouillon et al. (2017) applied the XRF for measuring $\mathrm{Mn}, \mathrm{Zn}$ and $\mathrm{Pb}$ at metal-contaminated sites. Dong et al. (2016) revealed the use of spectral data for estimating heavy metals in mining reclamation areas. Aldabaa et al. (2015) demonstrated the feasibility of using proximal (potable-XRF and VNIR) sensing for rapid soil salinity quantification; while other studies also shown comparable potential for using the abovementioned techniques for prediction of organic matter (Morona et al., 2017) and pH value (Sharma et al, 2014) in soil.
All of the proposed approaches are expected to be used as alternatives for conventional analytical techniques to provide reliable environmental monitoring results. But chemometric treatment, such as multi-linear regression, stepwise multi-linear regression, partial least squares regression, on the spectral data all played an important role in improving the accuracy on the prediction models (Gredilla et al., 2016; Dörnhöfer \& Oppelt, 2016).

This study aims to explore the feasibility of using nondestructive spectrometer optical instruments, including high Spectrometer (VNIR) and potable X-ray fluorescence spectrometer (PXRF), for analysing the content of heavy metals in water bodies. Clarification on their applicability for field study is also addressed.

\section{RESEARCH METHODS}

\subsection{Water sample preparation}

The water samples evaluated in this study were prepared in our laboratory by diluting of stock solutions. Heavy metals of lead $(\mathrm{Pb})$, zinc $(\mathrm{Zn})$ and copper $(\mathrm{Cu})$ were selected as the target water constitutes in the study. Range of concentration are 5-10 $\mathrm{mg} / \mathrm{L}$ and $500-3000 \mathrm{mg} / \mathrm{L}$ for PXRF and VNIR, respectively.

\subsection{Heavy metal content measurement}

Two non-destructive spectrometer optical instruments, including high Spectrometer (VNIR, FieldSpec HandHeld 2) and potable X-ray fluorescence spectrometer (PXRF, Vanta MSeries), were selected in this study for estimating the content of heavy metals in water samples. A conventional chemical

\footnotetext{
* Corresponding author: mlee@nkust.edu.tw
} 
detection method of ICP-OES was used for comparison and elucidating the correlation between the approaches.

\subsection{Experimental setup}

Figure 1 reveals the experimental setup for the remote sensing technique using visible-near infrared spectroradiometer (VNIR). The sensing experiments were conducted in the light booth, which was intended to simulate the actual situation for field studies. The light booth enables the simulation of daylight and equipped with white interior as background reference. The water samples were stored in a quartz beaker during sensing measurements, in order to minimize the reflective interference from the beaker.

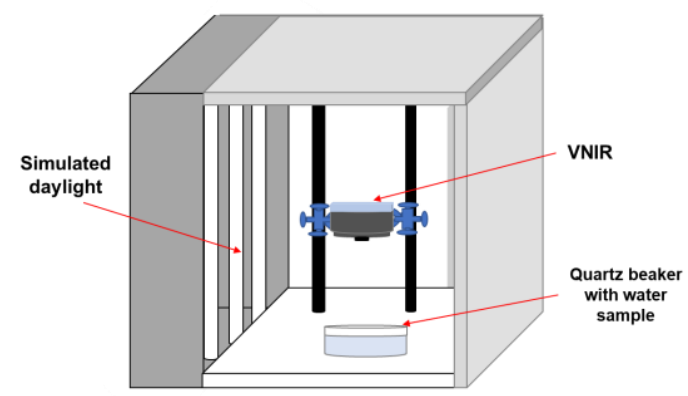

Figure 1. Setup of light booth for environmental simulation for sensing measurements

\section{RESULTS AND DISCUSSION}

\subsection{Identification of spectral characteristics}

Figure 2 shows the spectral data (from $800 \mathrm{~nm}$ to $1075 \mathrm{~nm}$ ) for the studied heavy metal using the environmental simulation setup proposed in this study. The spectral curves without pretreatment were relatively smooth with no abnormal reflection peaks, which were directly used to identify the sensitive bands for the target metals. The sensitive bands were characterized as $984 \mathrm{~nm}, 968 \mathrm{~nm}$ and $1024 \mathrm{~nm}$ for $\mathrm{Cu}, \mathrm{Zn}$ and $\mathrm{Pb}$, respectively. Spectral characteristics on other sensitive bands for the studied metals are provided in Table 1. It was shown that most of the sensitive bands for the studied heavy metals fall in the range from $800 \mathrm{~nm}$ to $1075 \mathrm{~nm}$, which were in line with the findings in Rostom et al.(2017).

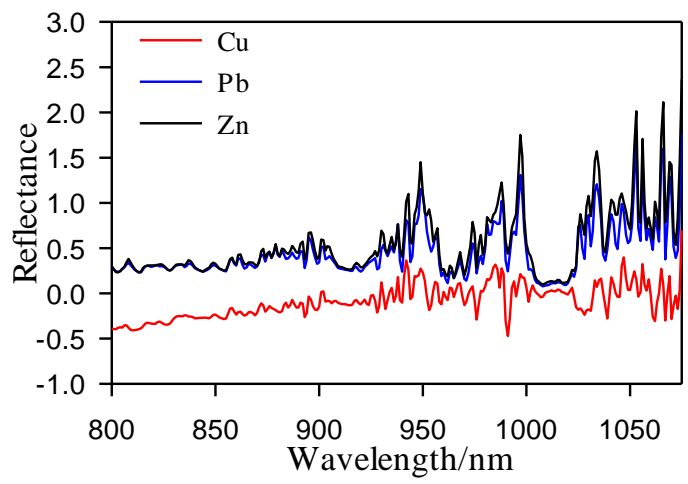

Figure 2. Spectral data for the studied metal elements (both of the samples are at $2000 \mathrm{mg} / \mathrm{L}$ )

Table 1. Spectral data for the studied metal elements

\begin{tabular}{cc}
\hline Metal & Spectral characteristics(nm) \\
\hline $\mathbf{C u}$ & $946 \cdot 984 \cdot 988 \cdot 997 \cdot 1047 \cdot 1065 \cdot 1075$ \\
$\mathbf{P b}$ & $951 \cdot 989 \cdot 997 、 1024 \cdot 1053 \cdot 1066 \cdot 1075$ \\
$\mathbf{Z n}$ & $949 \cdot 968 \cdot 996 \cdot 1034 \cdot 1041 \cdot 1069 \cdot 1074$ \\
\hline
\end{tabular}

Figure 3 presents the spectra for the studied metal elements at different concentration from $500 \mathrm{mg} / \mathrm{L}$ to $3000 \mathrm{mg} / \mathrm{L}$. It was observed that the reflectance on sensitive bands improved as increase of metal concentrations. Detail spectral data for the metals are provided in Table 2 to Table 4 . All of the findings suggested the need of data pretreatment or select of appropriate chemometric approach to improve the accuracy and reliability on prediction model (Dörnhöfer \& Oppelt, 2016)。
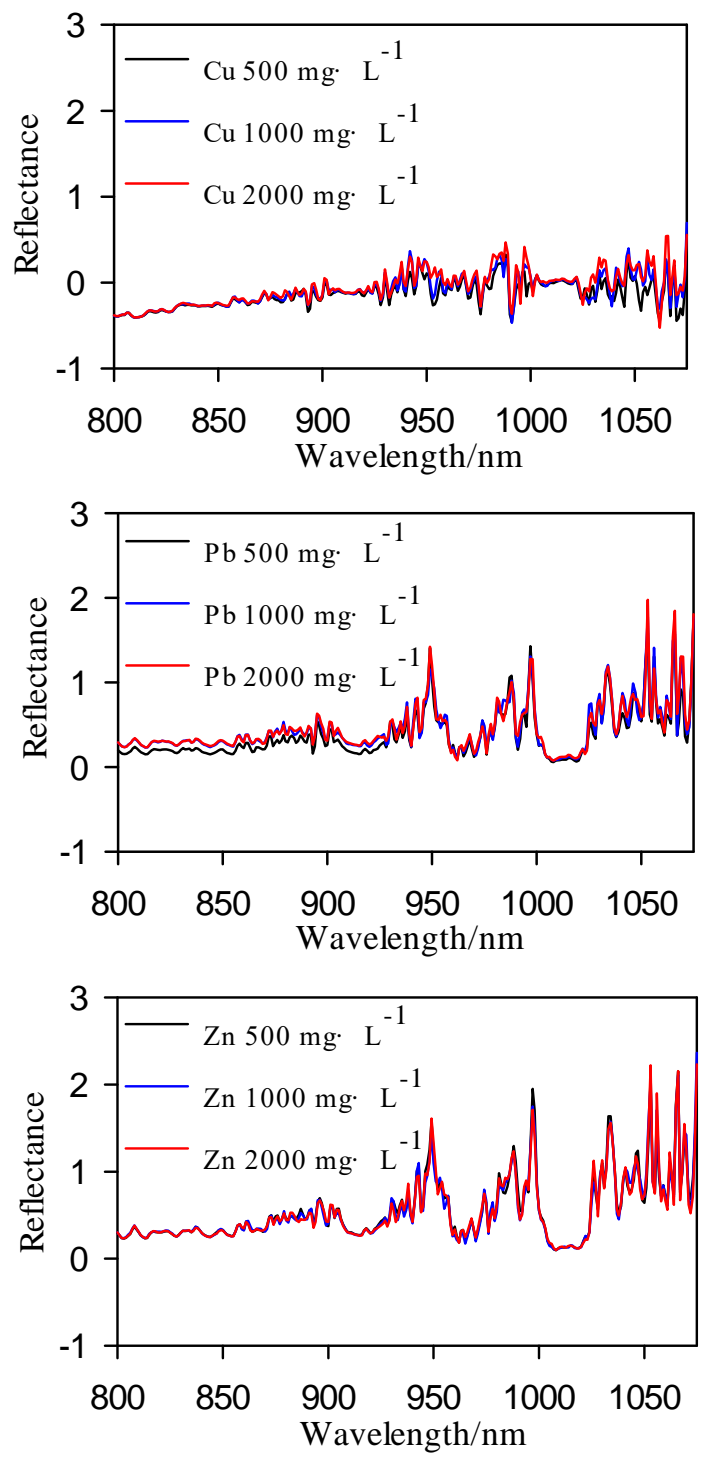

Figure 3. Spectra of the studied metal elements under different concentration (500 to $2000 \mathrm{mg} / \mathrm{L}$ ) 
Table 2. Reflectance characteristics at sensitive bands for $\mathrm{Cu}$

\begin{tabular}{cccc}
\hline Conc.(mg/L) & & & \\
Spectral(nm) & $\mathbf{5 0 0}$ & $\mathbf{1 0 0 0}$ & $\mathbf{2 0 0 0}$ \\
\hline $\mathbf{9 4 6}$ & 0.23 & 0.19 & 0.29 \\
$\mathbf{9 8 4}$ & 0.20 & 0.28 & 0.27 \\
$\mathbf{9 8 8}$ & 0.33 & 0.28 & 0.47 \\
$\mathbf{9 9 7}$ & 0.13 & 0.21 & 0.42 \\
$\mathbf{1 0 4 7}$ & 0.29 & 0.40 & 0.32 \\
$\mathbf{1 0 6 5}$ & 0.25 & 0.27 & 0.54 \\
$\mathbf{1 0 7 5}$ & 0.56 & 0.70 & 0.56 \\
\hline
\end{tabular}

Table 3. Reflectance characteristics at sensitive bands for $\mathrm{Pb}$

\begin{tabular}{cccc}
\hline Conc.(mg/L) & & & \\
Spectral(nm) & $\mathbf{5 0 0}$ & $\mathbf{1 0 0 0}$ & $\mathbf{2 0 0 0}$ \\
\hline $\mathbf{9 5 1}$ & 0.72 & 0.93 & 0.89 \\
$\mathbf{9 8 9}$ & 0.75 & 0.87 & 0.81 \\
$\mathbf{9 9 7}$ & 1.43 & 1.31 & 1.28 \\
$\mathbf{1 0 2 4}$ & 0.22 & 0.27 & 0.19 \\
$\mathbf{1 0 5 3}$ & 1.58 & 1.77 & 1.98 \\
$\mathbf{1 0 6 6}$ & 1.58 & 1.60 & 1.85 \\
$\mathbf{1 0 7 5}$ & 1.74 & 1.76 & 1.81 \\
\hline
\end{tabular}

Table 4. Reflectance characteristics at sensitive bands for $\mathrm{Zn}$

\section{Conc.(mg/L)}

\begin{tabular}{cccc} 
Spectral(nm) & $\mathbf{5 0 0}$ & $\mathbf{1 0 0 0}$ & $\mathbf{2 0 0 0}$ \\
\hline $\mathbf{9 4 9}$ & 1.58 & 1.45 & 1.61 \\
$\mathbf{9 6 8}$ & 0.45 & 0.46 & 0.46 \\
$\mathbf{9 9 6}$ & 1.28 & 1.26 & 1.19 \\
$\mathbf{1 0 3 4}$ & 1.64 & 1.57 & 1.56 \\
$\mathbf{1 0 4 1}$ & 1.02 & 1.04 & 1.05 \\
$\mathbf{1 0 6 9}$ & 1.37 & 1.45 & 1.55 \\
$\mathbf{1 0 7 5}$ & 1.32 & 1.48 & 1.27 \\
\hline
\end{tabular}

\subsection{Spectral estimation results}

Results from the spectral analysis were then be used for correlation analysis between the measured content and the spectral reflectance or elemental results.

Figure 3 shows the correlation of measured metal concentration in the validation samples (by ICP-OES) compared to the proposed non-destructive approach using PXRF. Significant correlation was obtained for the three studied metals, suggesting the high feasibility of using PXRF for detecting heavy metals in water samples. However, our results also validate the fact that the PXRF was not applicable for remote sensing application, as the intensity of fluorescence is inversely proportional to the distance between receptor and sample (Zhou et al., 2018).

Differently, the correlation between measured metal concentration and predicted results from non-destructive approach using VNIR were less significant but still at moderate levels, particularly for the $\mathrm{Pb}$ and $\mathrm{Zn}$. The relatively higher correlation found for $\mathrm{Cu}$ could be attributed to the blue color characteristic of the solution, whereas the others remain clear. Future research efforts are therefore suggested to apply various multivariate calibrations or data mining techniques for improving the accuracy of prediction models.

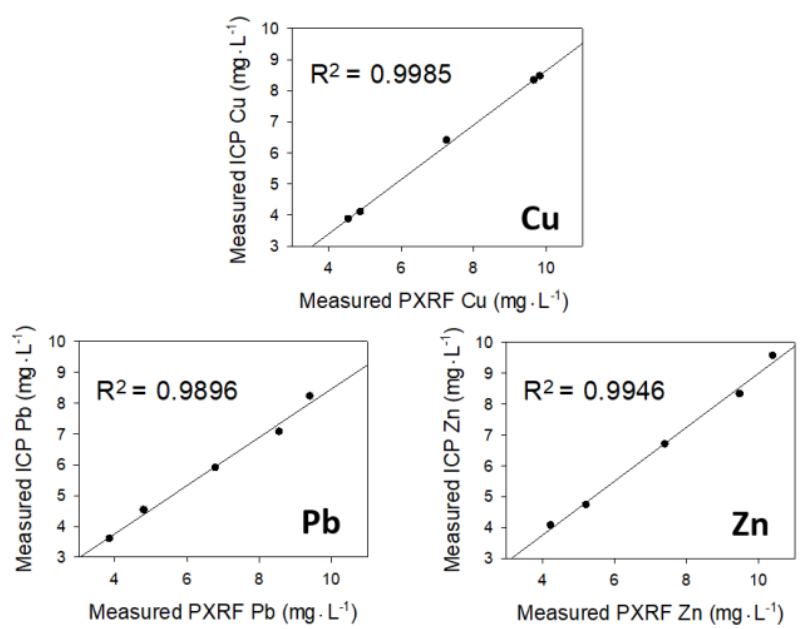

Figure 3. The measured metal concentration in the validation samples (by ICP-OES) compared to the proposed nondestructive approach using PXRF (at 8.9, 9.57, $89.94 \mathrm{keV}$ for $\mathrm{Cu}, \mathrm{Zn}, \mathrm{Pb}$, respectively)
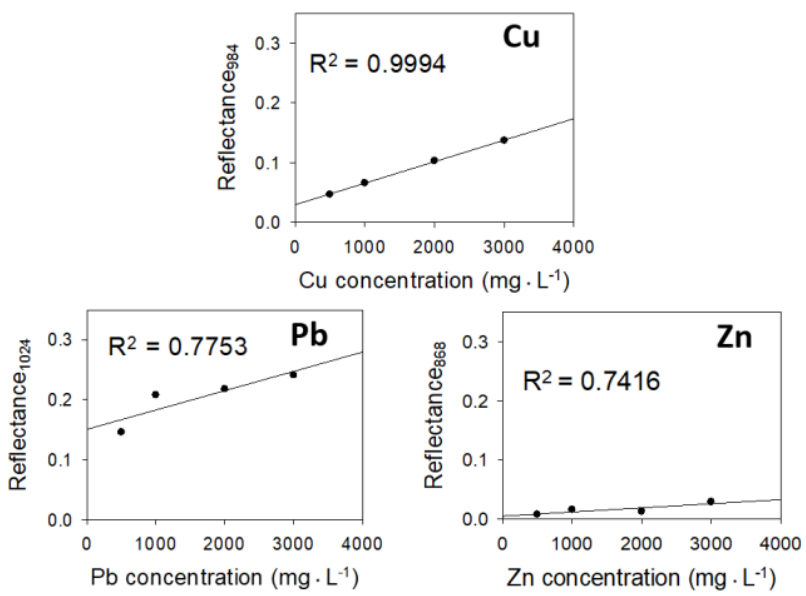

Figure 4. The measured metal concentration in the validation samples (by ICP-OES) compared to the proposed nondestructive approach using VNIR

\section{CONCLUSIONS}

The study demonstrated the use of non-destructive analytical methods, including PXRF and VNIR for quantification of metal contents $(\mathrm{Cu}, \mathrm{Pb}, \mathrm{Zn})$ in water samples. Reasonable agreements between the measurements from validated samples and PXRF were observed, whereas moderate correlations were perceived for simple linear regression model using spectral information from VNIR. Results from this study are expected to provide useful information on rapid identification of metal-polluting sources.

\section{ACKNOWLEDGEMENTS}

The authors are grateful for the research funding from the Ministry of Science and Technology in Taiwan through project number 107-2218-E-992 -305. 


\section{REFERENCES}

Aldabaa, A.A.A., Weindorf, D.C., Chakraborty, S., Sharma, A., $\mathrm{Li}$, B. 2015. Combination of proximal and remote sensing methods for rapid soil salinity quantification. Geaderma, 239$240,36-46$

Dong, J., Dai, W., Xu, J., Li, S. 2016. Spectral estimation model construction of heavy metals in mining reclamation areas. International Journal of Environmental Research and Public Health, 13, 640 .

Gredilla, A., Fdez-Ortiz de Vallejuelo, S., Elejoste, N., de Diego, A., Madariaga, J.M. 2016. Non-destructive Spectroscopy combined with chemometrics as a tool for Green Chemical Analysis of environmental samples: A review. TrAC Trends in Analytical Chemistry, 76, 30-39.

Morona, F., dos Santos, F.R., Brinatti, A.M., Melquiades, F.L. 2017. Quick analysis of organic matter in soil by energydipersive X-ray fluorescence and multivariate analysis. Applied Radiation and Isotopes, 130, 13-20.

Rouillon, F., Taylor, M.P., Dong, C. 2017. Reducing risk and increasing confidence of decision making at a lower cost: Insitu pXRF assessment of metal-contaminated sites.

Environmental Pollution, 229, 780-789.

Sharma, A., Weindorf, D.C., Man, T., Aldabaa, A.A.A., Chakraborty, S. 2014. Characterizing soils via portable X-ray fluorescence spectrometer: 3. Soil reaction $(\mathrm{pH})$. Geoderma, 232-234, 141-147.

Zhou, S., Yuan, Z., Cheng, Q., Zhang, Z., Yang, J. 2018. Rapid in situ determination of heavy metal concentrations in polluted water via portable XRF: Using $\mathrm{Cu}$ and $\mathrm{Pb}$ as example. Environmental Pollution, 243, 1325-1333.

de la Mare, W., Ellis, N., Pascual, R., Tickell, S. 2012. An empirical model of water quality for use in rapid management strategy evaluation in Southeast Queensland, Australia. Marine Pollution Bulletin, 64(4), 704-711

Dörnhöfer, K., Oppelt, N. 2016. Remote sensing for lake research and monitoring - Recent advances. Ecological Indicators, 64, 105-122.

Rostom, N.G., Shalaby, A.A., Issa, Y.M., Afifi, A.A. 2017. Evaluation of Mariut Lake water quality using Hyperspectral Remote Sensing and laboratory works. The Egyptian Journal of Remote Sensing and Space Science, 20, S39-S48. 